\title{
A CONSULTA MÉDICA NO CONTEXTO DO PROGRAMA SAÚDE DA FAMÍLIA E O DIREITO DA CRIANÇA ${ }^{+}$
}

\section{MEDICAL VISITS IN THE CONTEXT OF THE FAMILY HEALTH PROGRAM AND CHILDREN'S RIGHT}

Isabel Maria Sampaio Oliveira Lima*

Vânia Sampaio Alves**

Anamélia Lins e Silva Franco ${ }^{* * *}$

\begin{abstract}
Lima IMSO, Alves VS, Franco ALS. A Consulta médica no contexto do programa saúde da
\end{abstract} família e direito da criança. Rev Bras Crescimento Desenvolv Hum. 2007; 17(3):84-94.

\begin{abstract}
Resumo: Objetivo: Analisar a compreensão do médico de saúde da família em relação ao direito à saúde da criança. Método: Observaram-se 50 consultas médicas com crianças menores de seis anos de idade, conduzidas por dez médicos de saúde da família com atuação em três municípios baianos. As consultas foram registradas em áudio e, posteriormente, transcritas na íntegra, mediante consentimento informado dos médicos e dos responsáveis pelas crianças. A análise das consultas obedeceu a duas etapas consecutivas e complementares em relação aos objetivos pretendidos: a descrição da condução das consultas e a análise interpretativa do processo interacional e comunicacional entre os médicos e as famílias das crianças assistidas. Resultados: A investigação aponta ser a consulta médica orientada pelas linhas de cuidado de atenção integral à saúde da criança. Contudo, entre os médicos predomina uma concepção restrita de saúde. Esta, ao circunscrever a queixa aos sintomas e à atenção estritamente medicamentosa, compromete a apreensão de seus determinantes, desvinculando-a da realidade das famílias e da comunidade. A consulta deixa de constituir uma oportunidade de afirmação do direito à saúde da criança. Conclusões: A investigação conclui que, na perspectiva do direito da criança, a atenção médica precisa ser orientada pelo princípio do seu "melhor interesse" nos termos da Convenção das Nações Unidas sobre o Direito da Criança. Esta constatação remete para a necessária afirmação do paradigma da proteção integral da criança e do adolescente na formação dos profissionais de saúde.
\end{abstract}

Palavras-chave: Política de Saúde. Programa Saúde da Família. Direito à saúde da criança.

\section{INTRODUÇÃO}

Os serviços públicos de saúde no Brasil são freqüentemente relacionados a conteúdos negativos, sendo acentuados, especialmente pelos veículos de comunicação de massa, aspectos tais como a restrição quanto ao acesso, à insatisfação dos usuários, a ineficiência e a ineficá-

+ Os dados analisados no presente artigo foram derivados do projeto de pesquisa "A relação médico-paciente no Programa Saúde da Família: uma pesquisa-ação com as equipes de saúde da família do Ceará e da Bahia”, desenvolvido sob financiamento do CNPq - Processo 521229/98.

* Juíza de Direito, Doutora em Saúde Pública (ISC-UFBA), Docente da Faculdade de Direito e do Mestrado em Família na Sociedade Contemporânea (UCSAL). Endereço para correspondência: Rua Carmem Miranda 326 Ap 902 Pituba CEP 41.810-670 Salvador-Bahia - E-mail: isabelmsol@ compos.com.br

** Psicóloga, Doutoranda em Saúde Pública (ISC-UFBA), Professora Substituta do Departamento de Saúde Coletiva (ISC-UFBA) - E-mail: vaniasampa@yahoo.com.br

*** Psicóloga, Doutora em Saúde Pública (ISC-UFBA), Docente do Mestrado em Família na Sociedade Contemporânea (UCSAL) - E-mail: anameliafranco@uol.com.br 
cia das ações produzidas. Em contrapartida, a proposição do Sistema Único de Saúde (SUS), cujos princípios e diretrizes preconizam a universalidade, a integralidade e a equiidade, constituiu uma conquista do povo brasileiro pela democracia da atenção à saúde.

O reconhecimento da saúde como um direito humano repercute tanto na formulação de políticas públicas quanto na prática profissional. A garantia dos direitos humanos, assim como a do direito à saúde da população e, em especial, da população infanto-juvenil, exige mais do que a afirmação normativa. Para efetivação do direito à saúde faz-se necessária a definição de políticas públicas específicas capazes tanto de superar um discurso retórico quanto de promover uma atuação articulada de diferentes atores sociais..$^{1-6}$ A garantia do direito à saúde do grupo populacional infanto-juvenil é resultante de múltiplos fatores de ordem política, socioeconômica, jurídica, cultural, ambiental e não exclusivamente de natureza física. ${ }^{7-9}$

A saúde, em sua acepção ampla, é concebida como expressão da qualidade de vida e está, portanto, estreitamente relacionada às condições de existência social, econômica e cultural. Nesta perspectiva, a atenção à saúde não deve ser restrita ao âmbito da clínica, cujo enfoque recai sobre o indivíduo, a doença e a assistência curativa. Em conformidade com esta concepção têm sido propostas ações extramuros. Estas ações se caracterizam pela construção de parcerias entre profissionais de saúde e usuários para o enfrentamento de problemas vivenciados pelas comunidades.

O Programa Saúde da Família (PSF) que, na conjuntura contemporânea da política de saúde nacional, tem sido estratégico no processo de construção e de fortalecimento do SUS, vem conferindo aos profissionais de saúde um novo contexto de prática e incitado à reformulação de saberes. A estratégia do PSF pretende oferecer uma atenção centrada nos princípios da vigilância da saúde. ${ }^{11,12}$ Assim sendo, a assistência prestada deve ser integral, abrangendo todos os momentos ou dimensões do processo saúde-doença. ${ }^{13,14}$ A abordagem da vigilância da saúde reconhece profissionais e usuários enquanto agen- tes da produção da saúde. Nesta direção, espera-se uma transformação da relação entre estes atores, particularmente da relação entre médico e paciente.

O objetivo do presente estudo é analisar a compreensão do médico de saúde da família em relação ao direito da criança. A superação do reducionismo biomédico e a assimilação da abordagem da vigilância da saúde são condições necessárias para a construção de uma relação médico-paciente sustentada no compromisso e na co-responsabilidade para enfrentamento dos problemas de saúde individuais e coletivos. ${ }^{15}$ Assim, a doença pode ser remetida aos seus macro-determinantes e a saúde, por sua vez, pode vir a ser reconhecida como um direito de cidadania. Entretanto, neste momento, estas formulações ainda são de natureza contra-hegemônica. Mesmo no contexto do PSF e a despeito de algumas experiências inovadoras, a concepção restrita de saúde ainda é predominante, sendo a relação médico-paciente orientada para a atenção curativa e a prevenção de agravos e redução de riscos à saúde individuais. ${ }^{15,16}$

Em conformidade com a abordagem da vigilância da saúde, a relação médico-paciente pode ser compreendida como uma instância de operacionalização dos direitos humanos. ${ }^{17}$ A compreensão dos problemas de saúde individuais e coletivos pode ser remetida a uma contextualidade social, política, cultural e econômica que implica os profissionais de saúde, indivíduos, comunidade e Estado na definição de estratégias de enfrentamento. As ações de saúde desenvolvidas, seja na clínica ou nos espaços comunitários, precisam contemplar a dinâmica do adoecimento individual e seus determinantes, podendo, nesta direção, apreender as dimensões do direito.

A natureza jurídica do direito à saúde é de caráter subordinante: o Estado é obrigado constitucionalmente a garanti-lo mediante políticas públicas. $\mathrm{O}$ direito da criança e do adolescente também constitui uma relação subordinante em face de outros atores: família, comunidade e Estado. Desde a Declaração de Genebra de 1924, primeiro documento internacional público relativo aos direitos da criança, encontra-se preconizado o seu direito a crescer e a se desenvolver 
em ambiente saudável. Somente com o avanço do processo de afirmação do paradigma de proteção integral, consubstanciado na Convenção das Nações Unidas sobre o Direito da Criança (CNUDC), em 1989, ficaram os Estados-partes obrigados a implementar os princípios desta norma. Em relação ao direito à saúde, especificamente o art. 24 da CNUDC afirma que a criança deverá gozar do mais alto nível possível de saúde, vinculando, ao longo deste dispositivo, medidas necessárias para redução da mortalidade infantil, para o desenvolvimento da atenção sanitária preventiva, para atenção médica prénatal e pós-natal às mães, para assegurar prestação de assistência médica mediante atenção primária, entre outros.

A relação do paradigma de proteção integral à infância-adolescência com o eixo da garantia do direito à saúde em face dos direitos humanos vem sendo amplamente discutida. ${ }^{17,18}$ A garantia do direito à saúde como afirmação das obrigações do Estado não é tema da circunscrição exclusiva de operadores jurídicos. Envolve, sobretudo, a atuação dos profissionais de saúde. Estes, uma vez atentos à sua condição de atores políticos, superando uma postura prescritiva, podem escutar a queixa da criança, enunciada diretamente ou pela mãe em uma consulta, articulando-a na perspectiva do direito.

O princípio do "melhor interesse da criança", reconhecido hoje como princípio constitucional por força do $\S 2^{\circ}$ do art. $5^{\circ}$ da Constituição Federal, ratificado pelo Brasil através do decreto 99.710/90, deve ser também um norteador da prática de todos os profissionais que atuam junto à população infantil. Profissionais de saúde capazes de estabelecer conexões reais com aspectos do direito - sem que para tanto precisem fazer curso jurídico - enriquecem a tessitura de uma esteira onde se trançam interesses que têm como foco a dignidade da pessoa humana. Tamanha a força deste princípio que o próprio texto constitucional pátrio a ele faz explícita referência mediante a expressão "prioridade absoluta" no art. 227.

Justifica-se o presente estudo pela relevância de plasmar os princípios organizativos do PSF e os princípios estruturadores da
CNUDC. Os primeiros são relativos à reorientação das práticas de saúde em coerência com a abordagem da vigilância da saúde, conferindo integralidade à atenção. Os segundos, considerando o compromisso ontogenético com a própria espécie humana, articulam o interesse superior da população infanto-juvenil, a importância da não discriminação e a efetividade do direito. Em que pese cada um destes aspectos, seja em relação às práticas de saúde no PSF, seja em relação à afirmação do direito da infância, constituir objeto de estudos contemporâneos ${ }^{15,17}$, ainda é restrita a produção teórico-empírica que contemple estas vertentes. Afinal, estas tendências guardam, de per si, um trilho fundante com o princípio da integralidade. O vagão que transporta a concepção de saúde na perspectiva deste princípio interessa aos profissionais do PSF, em especial ao médico. $\mathrm{O}$ vagão que transporta a concepção de direito da criança na perspectiva do princípio da integralidade interessa à família, à comunidade e ao Estado. Assim, os princípios que estruturam o atendimento do médico de saúde da família, quando na consulta à criança, estão articulados, sobretudo, na substância da integralidade. Incide nesta instância de atendimento o princípio da prioridade absoluta.

Através do cuidado com a saúde do paciente, o médico atua como tradutor de uma concepção de saúde. A formação do médico se projetará sobre a relação médico-paciente na medida em que o profissional imprime, no seu labor, uma matriz conceitual capaz de assimilar a perspectiva da integralidade da pessoa. $\mathrm{O}$ médico interpreta, mediante a relação com o paciente, aquilo que este lhe traz e pode, consoante a matriz que adote, remeter sintoma e queixa, resultado laboratorial ou dado clínico para uma esfera mais restrita ou mais ampla. É nesta dinâmica exegética que o profissional de saúde poderá sair da circunscrição formal da prática de saúde: ampliando o horizonte da práxis, densificando a relação com o paciente, articulando, através deste, a sua própria condição de cidadão. Ao fazêlo estará, quando do atendimento à criança e a sua família, operando o paradigma de proteção integral. 


\section{MÉTODO}

O dados analisados no presente estudo derivam da pesquisa "A relação médico-paciente no Programa Saúde da Família: uma pesquisa-ação com as equipes de saúde da família do Ceará e da Bahia" desenvolvida sob financiamento do CNPq. Com o objetivo de caracterizar a relação médico-paciente no contexto de práticas das equipes de saúde da família, observaram-se, no Estado da Bahia, 408 consultas ambulatoriais realizadas por vinte médicos do PSF de três municípios selecionados segundo critério geográfico: regiões metropolitana, litorânea e semi-árido.

A gravação das consultas realizou-se sob consentimento dos sujeitos participantes. Os médicos assinaram termo de consentimento informado. Os pacientes eram informados quanto ao trabalho do observador que estaria concentrado na atuação do médico. Evitando-se o constrangimento de apresentar um documento para ser lido e assinado por uma população com baixo nível de escolaridade, decidiu-se pelo consentimento verbal do paciente, registrado em áudio.

O projeto para análise das consultas no presente estudo foi submetido ao Comitê de Ética em Pesquisa do Instituto de Saúde Coletiva (ISC/ UFBA), recebendo deste um parecer favorável.

O corpus de análise desta investigação foi constituído pela transcrição literal de 50 consultas de crianças menores de seis anos conduzidas por dez médicos assim distribuídos: cinco na região litorânea, três na metropolitana e dois no semiárido, respectivamente. Os médicos foram selecionados a partir do critério de atendimento de pelo menos quatro crianças no conjunto das consultas observadas. A definição quanto ao número de consultas a ser analisado por profissional considerou o objetivo de aproximação com a rotina do médico na atenção à saúde da criança.

A constituição do corpus foi seguida por duas etapas de análise consecutivas e complementares em relação aos objetivos pretendidos: a descrição da condução das consultas e a análise interpretativa do processo interacional e comunicacional entre os médicos e as famílias das crianças assistidas.

\section{RESULTADOS E DISCUSSÃO}

\author{
Atenção à saúde e ao direito da criança: a \\ consulta médica
}

Neste estudo a análise da atenção médica à saúde da criança privilegia a dimensão da relação médico-paciente, assumindo como diretrizes norteadoras da compreensão da prática médica as linhas de cuidado para uma atenção integral às crianças, definidas pelo Ministério da Saúde ${ }^{19}$ : a) ações da saúde da mulher; b) atenção à gestante e ao recém-nascido; c) promoção do aleitamento materno e alimentação saudável, com prevenção do sobrepeso e obesidade infantil, e combate à desnutrição e anemias carenciais; d) acompanhamento do crescimento e desenvolvimento; e) imunização; f) atenção às doenças prevalentes na infância; g) atenção à saúde bucal; h) atenção à saúde mental; i) prevenção de acidentes, maus-tratos/violência e trabalho infantil; j) atenção à criança portadora de necessidades especiais. Em relação às linhas de cuidado, salienta-se que, em todos os níveis e contextos de assistência, o encontro de profissionais de saúde com a criança e sua família deve ser potencializado para uma atenção privilegiada e integral à criança.

A maioria das crianças assistidas nas consultas analisadas era do sexo feminino (56\%) e tinha a mãe como acompanhante $(86 \%)$. Entretanto, outros cuidadores podiam apresentar-se ao atendimento, como o pai, a tia, a avó ou outra pessoa da rede social e comunitária. Deste modo, nestas consultas tem-se caracterizada uma relação médico-família.

Para $60 \%$ das crianças atendidas, realizava-se uma consulta ou procedimento de acompanhamento na unidade de saúde. As consultas foram motivadas por problemas de saúde diversos, principalmente doenças respiratórias e dermatites, como também pelo agendamento do próprio serviço para o acompanhamento do crescimento e desenvolvimento, sem que, necessariamente, houvesse a apresentação de uma queixa relativa à saúde da criança.

Em relação ao agendamento das consultas, prática que corresponde a uma dinâmi- 
ca vinculante das equipes do PSF com as famílias, identifica-se o princípio da co-responsabilidade previsto no art. 227 da Constituição Federal e dos artigos $7^{\circ}$. a 14 do Estatuto da Criança e do Adolescente (ECA). Configurase, mediante o agendamento, a continuidade exigida às políticas sociais previstas no art. 87 do ECA. Estas políticas correspondem às de atendimento dos direitos humanos na categoria dos direitos sociais: saúde e educação. Deverão, como tal, observar a três condições: universalidade, gratuidade e continuidade. Enquanto política de atendimento dos direitos da criança, segundo previsto no art. 86 do ECA, é implementada através de um conjunto articulado de ações governamentais e não governamentais da União, dos Estados, do Distrito Federal e dos Municípios.

O comparecimento da criança cuja família observa o agendamento, independentemente de queixa, se reveste de oportunidade excepcional para que o médico de saúde da família promova uma relação diferenciada na pauta da agenda de direito. Uma vez que o médico, atendendo à criança, compreenda que esta se constitui uma pessoa em fase peculiar de crescimento e desenvolvimento, deverá agir, independentemente da queixa apresentada pela família, na perspectiva da sua integralidade, com características e necessidades diferentes a cada momento da fase infanto-juvenil. Entende-se que a integralidade compreende crianças numa perspectiva ontogenética, na dinâmica da sua condição humana, social, biopsíquica, plasmando-se na concepção de sujeito de direito, com existência completa, histórica e temporalmente definidas, sob as influência de seu meio e sob a proteção da família, da sociedade e do Estado. ${ }^{17}$

O médico de saúde da família representa o Estado perante o usuário e a comunidade. É através da relação estabelecida pelo profissional que alguns fatores determinantes no êxito dos resultados quanto à saúde da criança podem ser implementados: aqueles fatores que dependem do comportamento individual (da mãe ou de outro cuidador) relativamente aos níveis atitudinais, cognitivos e comportamentais. ${ }^{17,20}$
O encontro entre o médico, a criança e sua família: a condução da consulta

A consulta de crianças apresenta particularidades importantes. A primeira delas diz respeito à presença da família que inquestionavelmente desempenha o papel de agente de cuidado e atenção à sua saúde. Uma segunda particularidade refere-se ao acentuado enfoque à preservação da saúde e integridade da criança, de maneira que, mesmo em situações de adoecimento, o discurso de famílias e profissionais tem como ponto de convergência a saúde e sua promoção.

A condução das consultas analisadas assume duas tendências principais. A primeira, típica da atuação de dois profissionais, consiste numa abordagem centrada na queixa motivadora da procura pelo serviço. Assim sendo, o exame físico é orientado pela queixa e outros problemas ou necessidades de saúde da criança não são investigados. Esta tendência de condução das consultas caracteriza-se, ainda, pela não compreensão da família como unidade de atenção, com a abordagem médica destacando a criança de seu contexto familiar e comunitário, contrariando, portanto, o teor do art. $4^{\circ}$ do ECA.

A segunda tendência identificada caracteriza-se como predominante na condução da consulta de crianças entre os demais profissionais. Esta tendência evidencia uma abordagem que, sem desconsiderar os problemas de saúde manifestos, amplia a investigação de outras necessidades de saúde da criança e, eventualmente, de sua família. Segundo esta tendência, a consulta não inicia necessariamente pela apresentação da queixa e descrição de sintomas, podendo ser priorizada a abordagem de outras temáticas, como a atualização das vacinas, o peso da criança, a sua amamentação ou alimentação.

A anamnese clínica e o exame físico nestas consultas caracterizam-se pela sua amplitude: além do esclarecimento diagnóstico possibilitam a investigação de outros problemas e necessidades de saúde, não se restringindo, assim, à mera queixa. Em uma consulta de uma criança de 10 meses com infecção na pele, o médico indaga a mãe: "Fora a pele, você acha a saúde dela boa?". 
A anamnese parece orientada para o diagnóstico de doenças prevalentes na infância, com os profissionais atentando especialmente para sintomas como: febre, chiado no peito, condição da urina e das fezes, diarréia, perda de apetite, secreção do ouvido, vômito, vermelhidão da garganta, tosse, gripe, obstrução e secreção nasal. Além da observação da criança, a anamnese pode ser estendida a outros membros da família, com o médico indagando se há mais alguém doente em casa. A saúde da mãe, particularmente a questão do planejamento familiar, também pode ser abordada pelo médico. Um profissional, atendendo uma criança de 6 meses, cuja mãe é adolescente inscrita no programa de planejamento familiar, questiona sobre o método contraceptivo usado pela jovem para evitar uma segunda gestação.

Assim como a anamnese, a atenção clínica pode ser estendida a outros membros da família. Em uma consulta na qual se constata a desnutrição de uma criança de um ano, a mãe, gestante de 8 meses, é encaminhada pelo médico para acompanhamento com a enfermagem: "Eu vou passar a senhora pra enfermeira que ela vai fazer o acompanhamento da desnutrição do neném, viu?".

A avaliação do peso e atualização das vacinas, mediante apreciação do Cartão da Cri$a n c ̧ a$, é um procedimento realizado sistematicamente na grande maioria das consultas. A atualização das vacinas, assim como a importância da apresentação do cartão em todas as consultas infantis e nos procedimentos na unidade de saúde, é ressaltada pelos profissionais. O Cartão da Criança configura um direito conquistado na perspectiva da redução de doenças imunopreveníveis, que, ao ser incorporado às ações cotidianas do PSF, pode constituir, de forma indireta, um instrumento de avaliação da qualidade da atenção prestada pela equipe de saúde da família à comunidade adscrita, bem como de observância de garantia do direito à saúde da criança.

Com relação ao peso da criança, a atenção médica é orientada para o diagnóstico de desnutrição. O tema da alimentação acompanha frequientemente a abordagem quanto ao peso da criança. A amamentação é incentivada. O desmame e a qualidade nutricional da alimentação das crianças são temas centrais nas orientações médicas de atenção e cuidado à sua saúde. Com relação à vacinação, ao peso e à alimentação das crianças, verifica-se uma preocupação entre os profissionais em garantir a promoção de um cuidado às crianças por suas famílias. Este cuidado legitimado como ideal por vezes não assimila as particularidades contextuais do cuidado que é real, alicerçando-se no discurso médico de prevenção de agravos e de redução de riscos à saúde.

O exame físico complementa a anamnese médica, consistindo, freqüentemente, de uma avaliação da condição geral da criança e de seu crescimento e desenvolvimento. A mãe ou outro acompanhante da criança na consulta podem ser convocados a participar da realização do exame, observando a criança conjuntamente com o médico. Mediante o exame físico, os profissionais podem estimular a família a observar outras necessidades de atenção e de cuidado para eventuais problemas de saúde da criança. Nesta direção, ao examinar uma criança de 4 anos, cuja queixa é de dor de garganta e febre, o médico interroga a mãe sobre cuidados com a saúde bucal: "Por que não tá levando pro dentista, mãe? Olhe o dentinho aqui...”. O médico orienta a mãe a agendar uma consulta com o dentista da unidade imediatamente à conclusão do atendimento, explicitando a relação da saúde bucal com outros problemas: "Não pode ficar com esse problema do dente não, viu mãe? Isso aí já dá problema de garganta, viu?".

A atenção do médico a situações de vulnerabilidade nas famílias e investigação de sinais e sintomas sugestivos de violência ou maus-tratos contra a criança também pode ser efetuada durante o exame físico. Esta condução estaria coerente com o preconizado no art. 245 do ECA: "Deixar o médico, professor ou responsável por estabelecimento de atenção à saúde e de ensino fundamental, pré-escola ou creche, de comunicar à autoridade competente os casos de que tenha conhecimento, envolvendo suspeita ou confirmação de maus-tratos contra criança ou adolescente”. ${ }^{21}$ 
Apenas em uma das consultas observadas foi verificado que um profissional, no atendimento a uma criança de dois anos, então acompanhada por uma senhora da comunidade, mostrou-se atento a um possível indício de violência intrafamiliar. A queixa era de febre, vômito, tosse e diarréia. Durante o exame físico, uma cicatriz de queimadura chama atenção do médico, que indaga sobre a condição familiar e a circunstância da queimadura. Informado que a mãe da criança teria se descuidado com uma panela no fogão, que a criança vive com o pai, que ele confiou a esta senhora, ora acompanhante da criança, os cuidados com a filha, o médico nada mais indaga. $\mathrm{O}$ silêncio do profissional não repercute concretamente na proteção integral da criança. A condução desta consulta permite problematizar a abordagem médica quanto àquelas dimensões do cuidado e atenção à saúde da criança que não são da esfera biomédica.

Nesta perspectiva, uma consulta conduzida por outro profissional aponta a limitação da atuação do médico de saúde da família na promoção do direito da criança e do adolescente. Trata-se da consulta de uma criança de um ano e meio de idade acompanhada da sua jovem mãe: uma adolescente de 16 anos. A criança já vem sendo acompanhada pelo médico, que a encaminhou, em consulta precedente, para uma avaliação com neurologista e fisioterapeuta, em razão da constatação de uma deficiência motora e atraso no desenvolvimento e crescimento. Na consulta analisada, agendada para acompanhamento, a criança apresenta febre e tosse. Verificase, durante o seu exame, que esta perdeu cerca de um quilo desde a última consulta. A avaliação solicitada com outros profissionais de saúde ainda não fora realizada, tendo a mãe argumentado que estaria aguardando o encerramento do período de festas populares para levar a criança ao hospital. Diante de tal justificativa, o médico censura a jovem: "Minha filha, deixa eu te falar, as festas não vão passar tão cedo!".

O médico imprimiu nesta consulta um caráter repreensivo à mãe adolescente. $\mathrm{Na}$ oportunidade não se identificou uma atenção compreensiva e assimiladora da condição familiar, porquanto, ainda que não fosse objeto imediato da consulta, ali se vislumbrava uma situação complexa passível de atenção médica. A adolescente se refere ao companheiro como "o homem que eu moro", comentando estar grávida, estimando dois meses de gestação. A jovem estava inscrita no programa de planejamento familiar, mas, segundo informa, deixou de usar o anticoncepcional oral e o companheiro não usava camisinha: "porque eu parei de tomar o remédio e eu não peguei camisinha, porque o homem que eu moro disse que não queria camisinha, que ele não gosta de camisinha não". A abordagem médica, todavia, culpabiliza a adolescente pela sua condição. A atenção à saúde da criança, diante desta condição, restringe-se à unidade de saúde, sendo o bebê medicado no âmbito do serviço, sem outro encaminhamento. Afirma-se, neste procedimento, a incapacidade da mãe em exercer o cuidado da criança, mas, em contrapartida, uma possível rede de apoio familiar e/ou comunitário não é acionada, reiterandose a culpabilização da mãe adolescente. Desta forma, a co-responsabilidade da família, da comunidade e do Estado, conquistada no caput do art 227 da Constituição Federal, se depara com a atuação estritamente biomédica. $\mathrm{O}$ espaço da relação médico-família se restringe uma vez que medidas de proteção à criança, nos termos do art. 98, inciso II, assim como aquelas previstas nos incisos IV e V do art. 101 ambos do ECA, deixam de ser promovidas. Tampouco o conselho tutelar, nos termos do art. 136 deste estatuto, é acionado pelo serviço de saúde.

A condução das consultas analisadas se desenvolve coerentemente com as linhas de cuidado para uma atenção integral à saúde da criança. ${ }^{19}$ Nesta perspectiva, as consultas das crianças menores de seis anos contemplam a investigação de temáticas como: imunização, acompanhamento do crescimento e desenvolvimento, alimentação e prevenção de desnutrição e anemias carenciais, atenção às doenças prevalentes na infância. Outras temáticas, ainda que observadas em consultas isoladas, também são abordadas: a saúde da mulher (planejamento familiar), a saúde bucal e os maus-tratos contra criança. Entretanto, a integralidade desta atenção mostra-se comprometida pela descontextu- 
alização do processo saúde-doença-cuidado. As condições concretas de vida das famílias não são assimiladas na compreensão dos problemas de saúde, o que obscurece um reconhecimento quanto à possibilidade de exercício de um cuidado das famílias afetivo e efetivo com a saúde de suas crianças. Depreende-se, portanto, que a atenção à saúde da criança não tem sido desenvolvida segundo a abordagem da vigilância da saúde. Identifica-se, ademais, que mesmo sendo relevante a observância das linhas de cuidado integral ${ }^{19}$, múltiplas são as circunstâncias que ensejam, durante a consulta médica, uma atuação eficaz na perspectiva do direito.

$\mathrm{Na}$ atenção às crianças, depreende-se uma concepção de saúde equivalente à ausência de doença. Assim, a preservação de sua saúde implica na adoção de medidas que se antecipem à manifestação da doença ou do agravo à saúde, repercutindo, assim, na importância do controle da vacina e do peso, bem como da qualidade da alimentação. Às famílias, delega-se a tarefa da constante vigilância, sendo esta exercida conjunta e complementarmente com os profissionais de saúde.

$\mathrm{A}$ atenção conferida às famílias se realiza dentro de uma perspectiva biomédica. Nesta direção, o cuidado de outros membros da família pode ser referido em caso de adoecimento ou de prevenção de agravos, como é o caso do planejamento familiar. Todavia, a dinâmica familiar não tem sido constituída como objeto de atenção e cuidado necessário e imprescindível à integralidade da assistência às crianças. Afinal, constitui a família primeiro círculo estruturante do desenvolvimento infanto-juvenil ${ }^{22}$ e tratá-la sem considerar a sua natureza essencial é fragmentar o direito à saúde da criança. A integralidade da atenção à saúde da criança plasma o conteúdo precípuo do seu interesse superior, afirmado na CNUDC, e, portanto, não poderá prescindir da perspectiva fundante do direito à saúde enquanto direito humano.

A concepção restrita de saúde entre os médicos de saúde da família

As narrativas das famílias se caracterizam pela sua brevidade e expressão monossilábica. $\mathrm{Na}$ maioria das consultas, estas são limitadas à apresentação da queixa e descrição de sintomas, podendo ser estimuladas pelos médicos nesta direção, de modo a oferecer informações mais detalhadas para o esclarecimento do problema. Assim sendo, segue-se à queixa de gripe indagações tais: "Como é a gripe dela? Aonde é?".

Em contraste com a brevidade dos relatos das famílias, a narrativa dos médicos é construída tendo como alicerce o exame físico e os exames laboratoriais, que ditam o diagnóstico e orientam a definição do projeto terapêutico. A causalidade dos problemas de saúde é investigada enquanto mera disfunção orgânica, desconectada da esfera familiar e comunitária. Mesmo as queixas cujos determinantes possam ser rapidamente remetidos às condições de vida, tais como verminoses, dermatites, diarréia e anemia, identifica-se um padrão da relação do médico de saúde da família com o binômio criança-cuidador de natureza eminentemente pontual.

A forma como são compreendidas as infecções de pele, por exemplo, enquanto agravo comum às crianças atendidas, passa a revelar uma concepção restrita de saúde. Um caso ilustrativo é observado entre as consultas de um profissional no atendimento a uma criança com 10 meses de idade, cuja família é residente em assentamento do Movimento dos Sem-Terra (MST). A criança, acompanhada pelo médico na unidade de saúde, tinha uma prescrição anterior para o "problema de pele" - segundo enunciado médico. Na consulta atual, a mãe fez considerações quanto à terapia adotada, observando que, mesmo seguindo as orientações do médico, as melhoras foram muito discretas. A investigação do problema é aprofundada, com o médico interrogando sobre os alimentos oferecidos à criança, a condição do ambiente doméstico e os cuidados de higiene. Indagada sobre o início da manifestação dos sintomas, a mãe, com precisão, relaciona esta ao comportamento de engatinhar da criança: "Ué, quando ela começou... logo, logo quando ela começou arrastar, assim seis meses, que ela começou arrastar, aí começou sair isso na pele assim, começou a sair os caroços. Aí quando pensou que não 
apareceu isso na pele dela...”. A condição de vida da família, entretanto, não é assimilada à compreensão do problema pelo médico, cuja suspeita diagnóstica é de alergia: "Então, esse problema da pele dela é um tipo de alergia”. $\mathrm{O}$ projeto terapêutico consiste em cuidados de higiene e com a alimentação da criança e a prescrição de um creme para o problema. Enfatizando a importância das orientações de cuidado serem observadas pela genitora, agendando o médico uma consulta subseqüente com a ressalva de que "a gente tem que descobrir a que essa alergia, se alergia somente, né?, a poeira, contato com chão...”.

A repercussão da medicalização dos "problemas de pele", isenta da abordagem sobre as condições dos ambientes domésticos e comunitários, pode ser dimensionada nas consultas em que a narrativa da família explicita a ineficácia das muitas pomadas prescritas. A narrativa da mãe de uma criança de seis meses, que apresenta o mesmo "problema de pele" há quatro meses, tendo feito uso de algumas pomadas, reitera a problemática: "Aí cheio de carocinho, aí quando passa o creme aí some e depois aparece".

Quanto às queixas de verminose e anemia, verifica-se uma lógica semelhante de condução da consulta: as condições de vida das famílias e seu contexto comunitário não são assimiladas à abordagem do problema. Assim como o "problema de pele", a verminose figura como uma queixa recorrente nas consultas. Para o seu enfrentamento, alguns profissionais adotam como prática a periodicidade de realização de exames e da prescrição de vermífugo. Desta forma, um médico compreende os exames como estratégia preventiva, uma vez que identifica muita "contaminação" na comunidade adstrita: "Olha, não passa muito tempo sem fazer os exames não, viu? Porque essa área tem muita contaminação, então é bom está sempre fazendo exames". Outro profissional, coerente com esta mesma racionalidade, dispensa, às vezes, a realização do exame laboratorial: "Então eu vou passando para ele um remédio de verme, já tem seis meses que ele tomou o remédio de verme... então eu tô repetindo agora”.
Embora assim não seja reconhecida pelos médicos, a família pode ser mais do que uma mera reprodutora de cuidados prescritos, constituindo-se sujeito do processo de cuidar das crianças. A autonomia das famílias no exercício de cuidado com a saúde das crianças pode não estar explícita nas consultas. A condução da consulta e a narrativa médica certamente não conferem um lugar para a expressão destas famílias proativas. Fora da clínica médica e paralelamente às práticas de cuidado recomendadas, há outras formas de cuidado exercidas, estejam os profissionais de saúde atentos ou não a este fato. Contudo, talvez a repercussão mais profunda e de caráter intangível desta prática médica, de natureza estritamente biomédica, seja a oportunidade perdida de conferir às famílias uma compreensão mais abrangente sobre a saúde, a doença e os cuidados de seus filhos. Enquanto infecções de pele, verminoses, anemias e diarréias são medicalizadas, restringe-se a capacidade de problematização e reflexão sobre as condições de vida e sobre os determinantes sociais dos processos saúde-doença. Em conseqüência, limita-se o alcance das intervenções destas famílias sobre a sua realidade para a promoção da qualidade de vida e do direito à saúde.

\section{CONCLUSÃO}

A atuação da equipe de saúde da família, quando efetivamente comprometida com o direito da população infanto-juvenil, pode estar implicada na promoção do direito à saúde da criança em cada procedimento. Entretanto, enquanto a abordagem clínica do médico de saúde da família circunscrever a queixa ao fenômeno físico, o encontro entre o médico, a criança e sua família dar-se-á, meramente, dentro do paradigma formal do cumprimento de um papel delineado: a prescrição de medicamentos visando a remissão de sintomas. Se a queixa, juntamente com outros elementos, possibilitar a apropriação, pelo médico, das condições de vida das crianças assistidas, o papel do profissional poderá superar a moldura da consulta. É nesta circunstância que se espera construir a perspectiva emancipatória 
junto à família da criança: uma vez que o médico proporcione meios de ir além da pontualidade da queixa, sua interlocução com a mãe ou responsável pela criança autorizará trazer para a consulta o espaço doméstico e comunitário, seus limites reais e suas potencialidades. Somente nesta dimensão agregadora é que se realiza o direito à saúde.

A assimilação da abordagem da vigilância da saúde à atenção à saúde da criança na atenção médica possibilita uma problematização do processo saúde-doença-cuidado que a concepção restrita de saúde, predominante nas consultas analisadas neste estudo, não estimula. Ao descolar os problemas e necessidades de saúde da criança do contexto de vida familiar e comunitário, o profissional de saúde limita, expressivamente, a sua atuação no sentido da promoção do direito da criança à saúde.

$\mathrm{Na}$ perspectiva do direito da criança, a atenção à saúde pelo médico do PSF precisa ser orientada, ainda, pelo o princípio do "melhor interesse da criança". Para tanto, a formação dos profissionais de saúde e, em especial, daqueles que integram a equipe do PSF, necessita contemplar o paradigma da proteção integral da criança e do adolescente, sob pena do Programa repetir uma formatação análoga à do paradigma que não reconhecia crianças e adolescentes enquanto sujeitos de direitos.

\begin{abstract}
Objective: To analyze the family health doctor's understanding of children's right to health. Methodology: Fifty medical visits with children under the age of six were observed. They were conducted by ten different family health doctors, in three different cities within the state of Bahia. With the express consent of the doctors and the children's guardians/parents, the visits were audio taped and, later, entirely transcribed. The visits' analysis consisted of two consecutive and complementary stages regarding the study's goals: a description of how the doctor conducted the visit, and an interpretative analysis of the interaction and communication between doctors and the children's families. Results: The investigation indicates that medical visits are guided by integral care concerning children's health; however, a restricted concept of health prevails amongst doctors. By limiting patient's complaint to symptoms and focusing on the medical treatment, medical visits jeopardize the understanding of its determinants, deviating from the reality of families and communities. Medical visits fail to be the grounds for the ratification of the children's right. Conclusions: The investigation concludes, from a perspective of the children's right, that medical care has to be guided by the "best interest of the children" principle according to the United Nations' Convention on the Rights of the Child. This evidence demonstrates the importance of incorporating the "integral protection of the child" paradigm into the education of health care providers.
\end{abstract}

Keywords: Health policies. Family health program. Children's right to health.

\section{REFERÊNCIAS}

1. Lafer C. Prefácio. In: Farias JE. Poder e legitimidade. São Paulo: Perspectiva; 1978. p.10.

2. Bidart Campos G J. Lo explícito y lo implícito en la salud como derecho y como bien jurídico constitucional. In: Mackinson G, Farinati A, coordenadores. Salud, derecho y equidad: princípios constitucinales, políticas de salud, bioética, alimentos y desarrollo. Buenos Aires: Ad-Hoc; 2001. p. 21-8.

3. Faria JE. A eficácia do direito na consolidação democrática. Revista Lua Nova 1993; 30: 35-72.

4. Mann JM, Gostin L, Gruskin S, Brennan T,
Lazzarini Z, Fineberg H. Health and human rights. In: Mann JM, Gruskin S, Grodin MA, Annas GJ, editores. Health and human rights: a reader. London: Routledge; 1999. p.7-20.

5. Marks S. Common strategies for health and human rights: from theory to practice. In: Mann JM, Gruskin S, Grodin MA, Annas GJ, editores. Health and human rights: a reader. London: Routledge; 1999. p. 397-416.

6. Van Bueren GV. Combating child poverty: human rights approaches. Human Rights Quarterly 1999; 21: 680-90.

7. Monteiro CA, Nazário CL. Evolução de condicionantes ambientais da saúde na infância 
na cidade de São Paulo (1984-1996). Rev Saúde Pública 2000; 34 (Supl 6): 13-8.

8. Duncan GJ. The effects of poverty on children. Future Child 1997; 7: 55-71.

9. Parker D, Sepúlveda C. Children's rights to survival and healthy development. In: Himes J. Implementing the Convention on the Rights of the Child. Florence: Unicef; The Hague: Martinus Nijhoff Publishers; 1995. p.69-106.

10. Newman-Williams M. Health as a fundamental right for all children. Promotional Education 1998; 5: 9-10.

11. Brasil. Ministério da Saúde. Saúde da Família: uma estratégia para a reorientação do modelo assistencial. Ministério da Saúde: Brasília; 1997.

12. Santana ML, Carmagnani MI. Programa Saúde da Família no Brasil: um enfoque sobre seus pressupostos básicos, operacionalização e vantagens. Saúde e Sociedade 2001; 10: 33-53.

13. Mendes EV. Um novo paradigma sanitário: a produção social da saúde. In: Mendes EV. Uma agenda para a saúde. São Paulo: Hucitec; 1996. p. 233-300.

14. Paim JS. Modelos de atenção e vigilância da saúde. In: Rouquayrol MZ, Almeida Filho N. Epidemiologia e Saúde. 6. ed. Rio de Janeiro: Medsi; 2003. p. 567-86.

15. Franco ALS. A relação médico-paciente no contexto do Programa de Saúde da Família: um estudo observacional em três municípios baianos [Tese de doutorado]. Salvador: Instituto de Saúde Coletiva, Universidade
Federal da Bahia; 2002.

16. Alves VS. Educação em saúde e constituição de sujeitos: desafios ao cuidado no Programa Saúde da Família [Dissertação de mestrado]. Salvador: Instituto de Saúde Coletiva, Universidade Federal da Bahia, Salvador, 2004.

17. Lima IMSO. Direito à Saúde: garantia de um direito humano para crianças e adolescentes. Estudo de Caso [Tese de doutorado]. Salvador: Instituto de Saúde Coletiva, Universidade Federal da Bahia; 2002.

18. Paula PAG. Direito da criança e do adolescente e tutela jurisdicional diferenciada. São Paulo: Revista dos Tribunais; 2002.

19. Brasil. Ministério da Saúde. Agenda de compromissos para a saúde integral da criança e redução da mortalidade infantil. Ministério da Saúde: Brasília; 2004.

20. Himes J. Implementing the Convention on the Rights of the Child. Florence: Unicef; The Hague: Martinus Nijhoff Publishers; 1995. p.69-106.

21. Brasil. Lei no. 8.069, de 13 de Julho de 1990. Dispõe sobre o estatuto da criança e do adolescente e dá outras providências. Diário Oficial [da] República do Brasil, Poder Executivo, Brasília, DF, 16 jul. 1990.

22. Lima IMSO, Alves VS. Retratos de exclusão social: a família e o adolescente em conflito com a lei na periferia de Salvador. In: Petrini JC, Cavalcanti VRS. Família, sociedade e subjetividades: uma perspectiva multidisciplinar. Petrópolis, RJ: Vozes; 2005. p. 111-31. 